\title{
Perancangan Sistim Monitoring Parkir Mobil Berbasis Web
}

\author{
Muhammad Irmansyah ${ }^{1}$, Efrizon $^{2 *}$, Roni Putra ${ }^{3}$ \\ ${ }^{123}$ Jurusan Teknik Elektro Politeknik Negeri Padang \\ mirmansyah38@gmail.com \\ Kampus Politeknik Negeri Padang, Limau Manis Padang
}

\begin{abstract}
This research is an information technology innovation for long distance monitoring system in realtime through WEB which applied to car parking system. This intelligent parking system is designed to solve the problems of parking car in Politeknik Negeri Padang. In this system, the driver gets information trough the web about the empty and the filled area in the parking. This system is an automated system using infrared and photodiode as sensor to identify the existences of the car in parking area and controlled by microcontroller. WEB to monitoring and inform the condition of slot parking area to the car driver using smartphone and can be accessed from everywhere at the web address ee.polinpdg.ac.id/parkir. Computer server is a WEB server and database server to save the program and monitoring data result.
\end{abstract}

\section{Keywords:monitoring, parking system, car, WEB}

Abstrak - Penelitian ini adalah inovasi teknologi informasi untuk sistim monitoring dari jarak jauh secara realtime melalui WEB yang diaplikasikan pada sistim parkir untuk mobil. Sistem parkir yang dibuat ini bertujuan untuk memecahkan salah satu masalah perparkiran mobil di Politeknik Negeri Padang. Dari sistim ini pengendara mobil dapat memperololeh informasi melalui WEB slot parkir kosong dan yang telah terisi. Sistem monitoring ini bekerja secara otomatis dengan memanfaatkan infrared dan photodioda sebagai sensor untuk mengidentifikasi ada tidaknya mobil pada slot parkir yang dikontrol oleh mikrokontroller. WEB untuk memonitoring dan memberi informasi kondisi dari slot parkir kepada pengemudi mobil melalui smartphone dari jarak jauh yang dapat diakses melalui alamat ee.polinpdg.ac.id/parkir. Komputer server berfungsi sebagai WEB server dan database server untuk penyimpanan program dan menyimpan data hasil monitoring

Kata kunci: monitoring, sistem parkir, mobil, WEB

(C) 2018Elektron Jurnal Ilmiah

\section{PENDAHULUAN}

Di era moderenisasi sistem parkir cerdas merupakan ide yang diharapkan dapat memberikan sedikit solusi terutama bagi pengemudi untuk mencari lokasi parkir kosong sebelum sampai di tempat parkiran. Selain efesien bagi pengemudi, sistem ini juga efektif bagi pengelola yang menyediakan lahan parkir untuk memberikan kenyamanan pengguna lahan parkir. Kemajuan teknologi komputerisasi dan otomatisasilah yang mendukung sistem parkir dapat dirancang dengan sedemikian rupa. Sistim parkir akan lebih efektif dan efisien dengan kompeterisasi yang tepat. Sistim parkir mampu memberikan kecepatan pelayanan, pengolahan data yang akurat sehingga data bisa langsung diproses dan muncul melalui WEB sehingga dapat diakses menggunakan smartphone. Permasalahannya bagaimana merancang sebuah inovasi teknologi informasi dan komunikasi untuk sistim monitoring dari jarak jauh secara realtime melalui WEB untuk sistim yang dapat menginformasikan lokasi parkir kepada pengemudi dan membantu mengarahkannya ke lokasi parkir yang kosong dengan menggunakan mikrokontroller dan WEB sebagai monitoring untuk diinformasikan kepada setiap pengendara sebelum sampai ke lokasi parkir.

Alat purwarupa sistem parkir yang dibuat ini bertujuan untuk memecahkan salah satu masalah perparkiran mobil di Politeknik Negeri Padang yakni penyampaian lokasi parkir kosong kepada pengemudi. Sistem ini merupakan sistem otomatis. Sistem dirancang dengan memanfaatkan mikrokontroller Arduino secara optimal dengan menggabungkan beberapa komponen-komponen yang lain. Alur kerja sistem diawali dengan pembacaan hasil kombinasi infrared dan photodioda sebagai sensor lokasi parkir yang kosong akan mengidentifikasi keberadaan mobil.

Seluruh proses akan dibaca dan diolah oleh mikrokontroller Arduino. Dan terakhir hasil pengolahan ditampilkan pada WEB sebagai informasi yang diberikan kepada pengemudi dan dapat diakses melalui smartphone dari jarak jauh. Temuan yang ditargetkan dari penelitian ini adalah inovasi teknologi informasi dan komunikasi untuk sistim monitoring dari jarak jauh secara realtime melalui WEB. Kemudian membuat client web server untuk komunikasi mikrokontroller pada jaringan Ethernet untuk sistim monitoring area parkir dan mengaplikasikan Ethernet Shield sebagai protokol 
Web Interface untuk pengiriman data antar perangkat sistim monitoring menggunakan protokoler http interface untuk komunikasi jarak jauh. Pembuatan sistim database pada server menggunakan MySQL untuk menyimpan data hasil monitoring.

\section{METODE PENELITIAN}

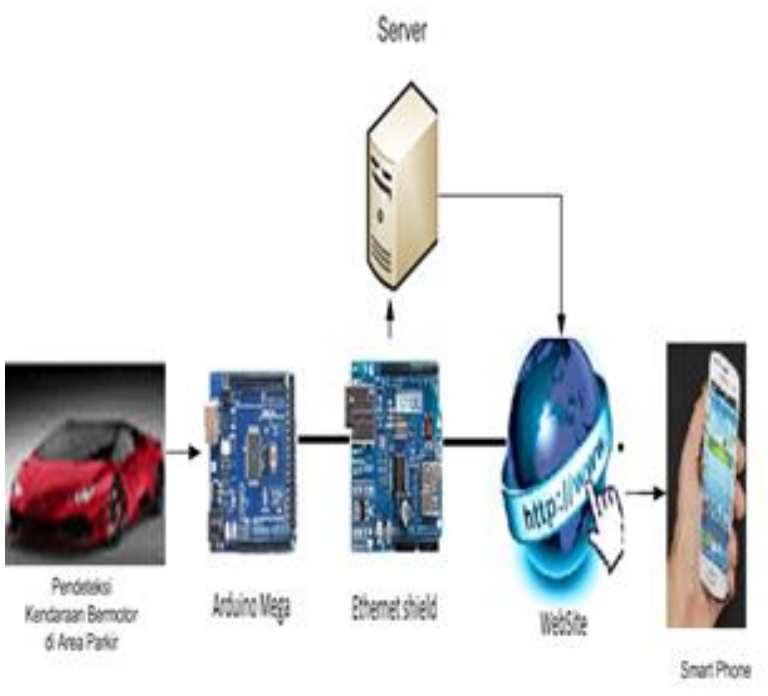

Gambar 1. Blok Diagram Sistim Parkir Mobil

Fungsi masing-masing blok pada gambar 1 adalah sebagai berikut :

1. Pendeteksi mobil berfungsi untuk mendeteksi ada tidaknya mobil di masing-masing slot parkir mobil pada area parkir menggunakan infrared dan photodioda.

2. Mikrokontroler Arduino Uno berfungsi untuk tempat pemorosesan pendeteksi ada tidaknya mobil di area parkir mobil.

3. Ethernet Shiled berfungsi untuk mengirim data sinyal digital dari mikrokontroller ke WEB server. Ethernet shield digunakan sebagai protokol untuk menghubungkan serta mengirimkan data dari WEB server sehingga bisa diakses melalui web.

4. Komputer server berfungsi sebagai WEB server dan database server untuk penyimpanan program dan menyimpan data hasil monitoring.

5. WEB berfungsi untuk monitoring jarak jauh dengan membaca seluruh data pada database server dan menampilkan data tersebut ke sisi client dengan menampilkan informasi kepada pengendara diarea parkir mana dan diblok parkir mobil mana yang masih kosong atau terisi mobil.

6. Smartphone berfungsi sebagai sarana untuk mengakses informasi berupa data kondisi area parkir yang akan dituju oleh pengendara mobil dengan cara masuk ke alamat WEB pada URL.

\section{HASIL DAN PEMBAHASAN}

\section{A. Bagian Slot Parkir Mobil dan Pendeteksi Mobil}

Pada sistim monitoring tempat parkir ini jumlah slot parkir untuk mobil sebanyak 4 buah slot. Masingmasing slot dipasang infrared dan photodioda yang berfungsi untuk mendeteksi ada tidaknya mobil yang diparkir pada slot parkir. Pada gambar 2 dapat kita lihat kondisi slot parkir dalam keadaan kosong dan slot parkir dalam keadan terisi mobil.
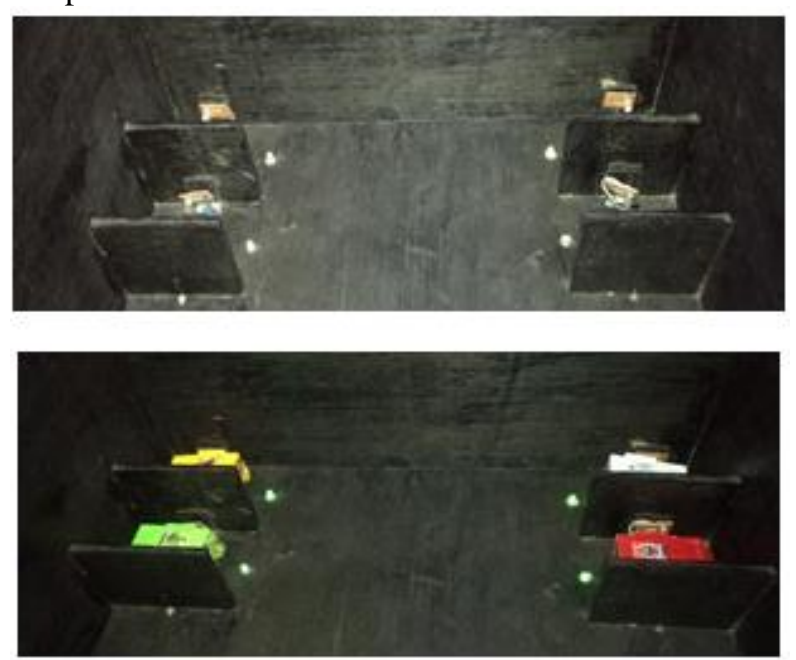

.Gambar 2. Slot parkir mobil saat kosong dansaat terisi mobil

Pengujian sensor photodioda dilakukan untuk menentukan apakah sensor yang digunakan dapat berfungsi dengan baik untuk mendeteksi ada tidaknya mobil di masing-masing slot parkir pada area parkir. Hasil pengujian sensor photodioda dapat dilihat pada tabel 1 .

\begin{tabular}{|c|c|c|}
\hline No & $\begin{array}{l}\text { Tegangan Output } \\
\text { Photodioda } \\
\text { (Volt) }\end{array}$ & $\begin{array}{l}\text { Kondisi Slot Parkir } \\
\text { Mobil }\end{array}$ \\
\hline 1 & 4 & Slot parkir kosong \\
\hline 2 & 0,5 & Slot parkir terisi mobil \\
\hline
\end{tabular}

Dari tabel 1 dapat kita lihat pada saat sensor photodioda mendapatkan cahaya dari infrared karena tidak adanya mobil yang parkir pada slot parkir maka tegangan output pada photodioda sebesar $4 \mathrm{~V}$. Hal ini disebabkan karena photodioda menerima cahaya dari infrared, sehingga intensitas cahaya yang diterima oleh photodioda sangat besar dan tahanan photodiode menjadi kecil sehingga arus yang mengalir pada photodioda juga menjadi besar, menyebabkan tegangan output photodioda menjadi besar.Pada saat sensor photodioda tidak mendapatkan cahaya dari infrared karena adanya mobil yang parkir pada slot parkir maka tegangan output pada photodioda sebesar $0,5 \mathrm{~V}$. Hal ini disebabkan karena photodioda tidak menerima cahaya dari infrared karena terhalang oleh 
mobil, sehingga intensitas cahaya yang diterima oleh photodioda sangat kecil dan tahanan photodioda menjadi besar sehingga arus yang mengalir pada photodioda juga menjadi kecil, menyebabkan tegangan output photodioda menjadi kecil.

\section{B. Bagian Sistim Monitoring Menggunakan WEB dan Database Kondisi Area Parkir}

Pada bagian ini menampilkan hasil pengolahan data dari kombinasiinfrareddan photodiodapada slot parkir untuk mendeteksi ada tidaknya mobil. Seluruhproses pendeteksian akandibacadandiolah oleh mikrokontroller. Hasil pengolahan data ditampilkan pada WEBdan dijadikan sebagai informasi yang diberikan kepada pengemudi mobil mengenai kondisi slot parkir mobil mana yang masih kosong dan yang sudah terisi dan informasi ini dapat diakses melalui smartphone secara real time dari jarak jauh. Untuk mengakses informasi dari WEB pemilik mobil bisa mengakses melalui alamat WEB ee.polinpdg.ac.id/parkir.

Selain itu pada server akan disimpan data hasil monitoring. Tampilan WEB sistim monitoring kondisi tempat parkir mobil dan tampilan database pada slot parkir yang masih kosong dapat kita lihat pada gambar 3.

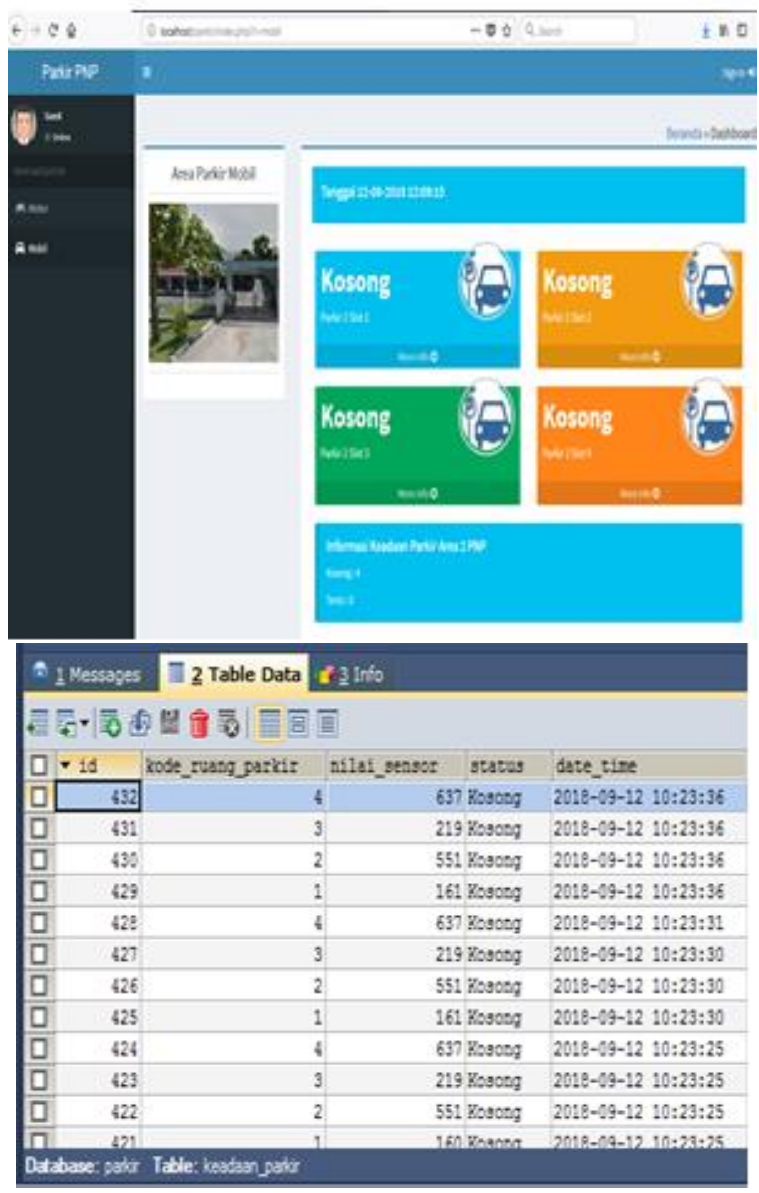

Gambar 3. Tampilan WEB slot parkir mobil dan database dalam keadaan kosong
Gambar 3 adalah tampilan WEB yang ada pada smartphone yang memberikan informasi slot parkir mobil. Pada tampilan WEB ini pengendara mobil dapat melihat keadaan slot parkir 1, slot 2, slot 3 dan slot 4 masih kosong. Bagian informasi pada bagian bawah WEB akan menampilkan informasi jumlah slot yang sudah terisi dan jumlah slot yang masih tersedia, pada tampilan diatas masih tersedia 4 slot parkir yang masih kosong. Sumber informasi kondisi slot parkir pada WEB ini diperoleh dari data hasil pendeteksian ada tidaknya mobil dari sensor infrared dan photodioda yang dikontrol melalui mikrokontroller.

Kemudian data tersebut dikirim dari mikrokontroller ke WEB server menggunakan ethernetshield sebagai protokol WEB interface sehingga bisa diakses oleh pengendara mobil melalui WEB. Pada gambar 3 juga diperlihatkan informasi yang ada pada database WEB server berupa kode slot parkir, data hasil pendeteksian sensor infra merah dan photodioda, status slot parkir apakah kosong atau terisi serta informasi tanggal, bulan, tahun dan jam masuk keluarnya mobil pada masing masing slot parkir. Tampilan WEB sistim monitoring kondisi tempat parkir mobil dan tampilan database pada slot parkir yang telah terisi oleh mobil dapat kita lihat pada gambar 4.
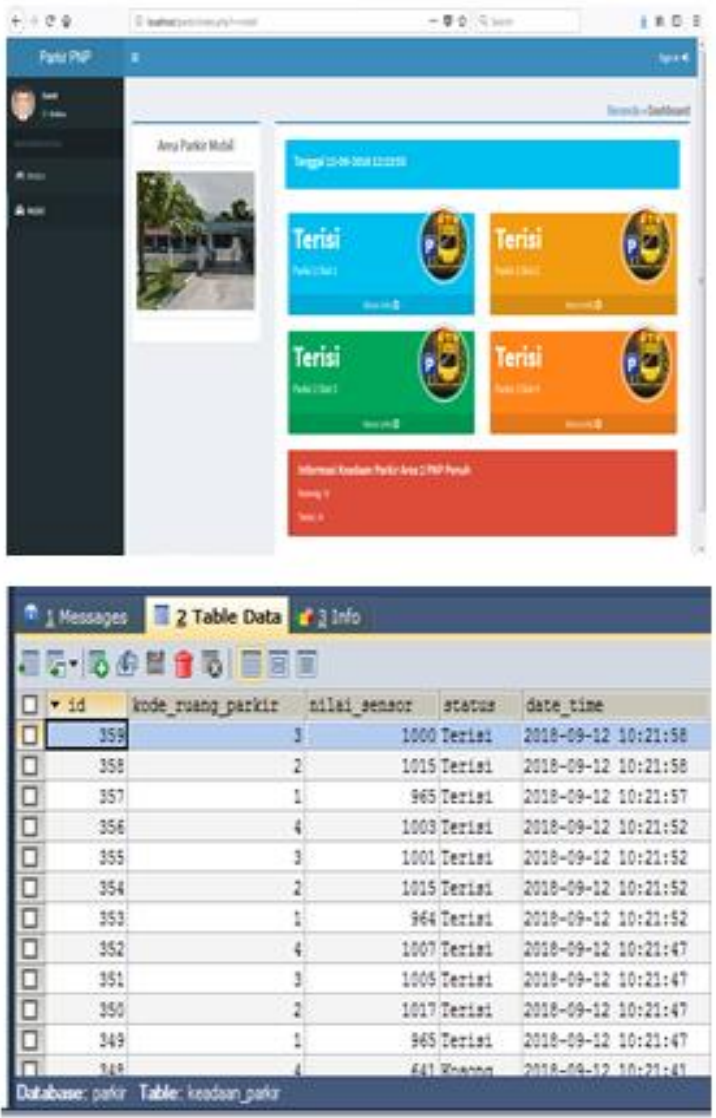

Gambar 4. Tampilan WEB slot parkir mobil dan database dalam keadaan terisi 
Pada gambar 4 dapat kita lihat tampilan WEB pada smartphone dimana WEB memberikan informasi bahwa slot parkir 1 , slot 2 , slot 3 dan slot 4 sudah terisi oleh mobil.Selain itu pada WEB server dapat dilihat informasi pada tanggal 12-09-2018 pada jam 10:21:41 slot 4 kosong. Slot 4 terisi pada jam 10:21:52, slot 1 terisi pada jam 10:21:57, slot 2 terisi pada jam 10:21:58 dan slot 3 jam 10:21:58. Semua aktivitas dari sistim monitoring ini berlangsung secara realtime setiap harinya

\section{KESIMPULAN}

1. Photodioda digunakan sebagai sensor pendeteksi ada atau tidaknya mobil yang terparkir pada slot parkir area parkir dimanategangan photodioda pada saat terhalang mobil sebesar $4 \mathrm{~V}$ dan tidak ada kendaraan dengan tegangan sebesar $1,5 \mathrm{~V}$.

2. Webdigunakan sebagai sistem penyedia informasi mengenai area parkir melalui smartphone oleh pemilik mobil pada saat akan menggunakan area parkir yang dapat diakses melalui alamat web ee.polinpdg.ac.id/parkir.

3. Database digunakan sebagai sistem informasi untuk mengetahui waktu masuk dan keluarnya kendaraan dari slot parkir dan untuk mengetahui nilai pembacaan data dari sensor infrared dan photodioda dan database ini bekerja secara realtime.

\section{UCAPAN TERIMA KASIH}

Penelitian ini merupakan Penelitian Terapan Unggulan Perguruan Tinggi yang didanai oleh dana DIPA Politeknik Negeri Padang, no: 192/PL9.1.4/LT/2018.

\section{REFERENSI}

[1] Amelia Yolanda,Irmansyah, 2015, "Rancang Bangun Prototipe Pintu Portal Berbasis Teknologi PLD", Penelitian Dosen Pemula

[2] Alfiyyah Azhar Ulfah, 2016, " Sistim Parkir Cerdas Terintegrasi WEB", Tugas Akhir

[3] Awallina Anjasnuari, 2015, "Perancangan Prototipe Sistim Parkir Cerdas Berbasis Mikrokontroller AtMega 8535”, Jurnal Ilmiah Saintikom Vol.14, No.2

[4] Dikky Chandra, Irmansyah, 2016, "Rancang Bangun Sistim Parkir Mobil Berbasis Mikrokontroller", Penelitian Dosen Pemula

[5] Darwin Priatna Syumbai, 2015, "Rancang Bangun Sistim Pengaturan Parkir Mobil Otomatis Berbasis Mikrokontroller", Tugas Akhir, STMIK PalComTech Palembang

[6] Elyas Palantei, 2015, "Pengembangan Sistim Perparkiran Cerdas Terintegrasi WEB", Jurnal Saintikom Vol.14, no.2

[7] Mahrus Sabang, 2016, "Smart Parking System", Tugas Akhir, STMIK Lammappapoleonro Soppeng

[8] Zaenab Muslim,2015, "Desain Aplikasi Berbasis WEB Interface Untuk Pemantauan Denyut Jantung", Department of Electrical Engineering, Hasanudin University 